\title{
A study to assess the knowledge of Scientometric among health care professionals
}

\author{
Manjula MJ ${ }^{1}$, Nalini G K ${ }^{2 *}$, Geetha Rathod $^{3}$ \\ ${ }^{1,3}$ Post Graduate, ${ }^{2}$ Professor and Head, Dept. of Pharmacology, Hassan Institute of Medical Sciences, Karnataka, India \\ *Corresponding Author: Nalini G K \\ Email: drnalinigk72@yahoo.com
}

\begin{abstract}
Introduction: Scientometric is a field of science dealing with quality assessment of the scientific validity of published articles. Now a days publication of articles made mandatory for assessing the academic performance of any profession. If authors are aware about scientometrics, they will be able to maintain the standard in their research work. Present study aimed to assess the knowledge of publication criteria among health care professionals and objected to know the knowledge about citation index, $\mathrm{H}$ index about publication.

Materials and Methods: 60 health care professionals who have completed their master degree, working at Sri Chamarajendra Hospital, HIMS, HASSAN who are willing to participate were given with validated questionnaire. The opinion generated for each question were expressed in percentage of the study group and results were analyzed.

Results: Out of 60 participants, $63.3 \%$ of them were attended training programme.

$68.77 \%$ were conducting language check before submission.

56.67\% knew what is COPE - Committee on Publication ethics and were following it. $66.67 \%$ knew that their paper will undergo Editorial - Peer review - Technical - Linguistic check.58.33\% knew about SCI - Science Citation Index and $41.67 \%$ of them were selecting the journals based on impact factor.38.33\% knew about $\mathrm{H}$ index and hardly $6.67 \%$ measuring the journal's $\mathrm{H}$ index before submitting their articles.

41.67\% have their online research ID and 26.67\% knew that citation metrics and $\mathrm{h}$ index calculated by these IDs

Conclusion: Every investigator must be made aware of citation index, impact factor and $\mathrm{H}$ index before writing/submitting their article for publication to maintain the quality of their publications.
\end{abstract}

Keywords: Scientometric, Impact factor, H index, Citation index, Health care professionals.

\section{Introduction}

Scientometric is a field of science dealing with quality assessment of the scientific validity of published articles and other type of publications. Worthiness of scientific journal is measured by the quality of articles published. The Impact factor (IF) - popular tool which analyses the quality of journal in terms of citations received by its published articles. Journals with high IF carry meaningful, prominent, and quality research. Other indices like $\mathrm{h}$ index, $\mathrm{g}$ index, $\mathrm{m}$ quotient, $\mathrm{c}$ index are some other alternatives to judge the quality of an author but each index has its own merits and demerits.

As, the pre-clinical and clinical research are the heart of our health care system, providing a promising article which has un-plagiarised data is the most important factor. If authors are aware about scientometrics, they will be able to maintain the standard in their research work. So, this study was conducted to assess the knowledge of health care professionals about Scientometrics and its importance.

\section{Materials and Methods}

All health care professionals who have completed master degree, working at Sri Chamarajendra Hospital, HIMS, HASSAN are included in the study. Those who are not willing to participate are excluded.

After IEC clearance, taking oral consent of60 health care professionals who have completed their master degree and willing to participate were given with validated questionnaire containing 15 questions including demographic data like name, specialty, post MD experience and their number of publications to give their feedback. 


\section{Statistical analysis}

Descriptive analysis was used. Percentage of the answers were taken to analyze the knowledge of the health care professionals about Scientometerics.

\section{Results}

Table 1: Out of 60 participated health care professionals, $85 \%$ were males and $15 \%$ were females.

\begin{tabular}{|c|c|c|c|}
\hline \multicolumn{4}{|c|}{ Number of participants $\mathrm{n}=60$} \\
\hline \multicolumn{3}{|c|}{ Male } & \multicolumn{3}{c|}{ Female } \\
\hline 51 & $\mathbf{8 5 \%}$ & 9 & $15 \%$ \\
\hline
\end{tabular}

Table 2: Knowledge of Health care professionals

\begin{tabular}{|l|l|c|c|c|}
\hline S. No & Questions & $\begin{array}{c}\text { Yes } \\
\text { In \% }\end{array}$ & $\begin{array}{c}\text { No } \\
\text { In \% }\end{array}$ & $\begin{array}{c}\text { NA } \\
\text { (Not attended in \%) }\end{array}$ \\
\hline 1. & $\begin{array}{l}\text { Have you attended any training for Scientific writing and } \\
\text { publishing? }\end{array}$ & 63.30 & 36.7 & 0 \\
\hline 2. & Do you know the term called 'Scientometric' & 43.33 & 56.67 & 0 \\
\hline 3. & $\begin{array}{l}\text { Have you read once recommendations by International committee } \\
\text { of Journal of medical editor's guidelines for publication? }\end{array}$ & 53.33 & 46.67 & 0 \\
\hline 4. & Did you know what is COPE - Committee on Publication ethics ? & 56.67 & 43.33 & 0 \\
\hline 5. & $\begin{array}{l}\text { Did you follow what is COPE - Committee on Publication ethics } \\
\text { (P)? }\end{array}$ & 56.67 & 43.33 & 0 \\
\hline 5. & $\begin{array}{l}\text { Do you know the types of review your paper will undergo after } \\
\text { submission (Editorial - Peer review - Technical - Linguistic } \\
\text { Review) }\end{array}$ & 66.67 & 33.33 & 0 \\
\hline 6. & Do you follow authorship criteria? & 66.67 & 33.33 & 0 \\
\hline 7. & $\begin{array}{l}\text { Are you familiar with various guidelines to write scientific paper } \\
\text { (Eg. CONSORT guidelines for clinical study reporting) }\end{array}$ & 58.33 & 41.67 & 0 \\
\hline 8. & Do you do yourself language check before submission? & 68.77 & 31.33 & \\
\hline & Plagiarism check before submission? & 39.12 & 60.88 & 0 \\
\hline 9. & Do you know about 'SCI - Science Citation Index'? & 58.33 & 41.67 & 0 \\
\hline 10. & $\begin{array}{l}\text { Do you select journal for publication based on impact factor by } \\
\text { Thomson routers SCI analysis? }\end{array}$ & 41.67 & 58.33 & 0 \\
\hline 11. & Do you know the term h index? & 38.33 & 58.34 & 0 \\
\hline 12. & Do you usually measure your citations and h index? & 6.67 & 90 & 3.33 \\
\hline 13. & $\begin{array}{l}\text { Do you know h index is used to evaluate scientific merit of a } \\
\text { publication? }\end{array}$ & 36.67 & 60 & 3.33 \\
\hline 14. & $\begin{array}{l}\text { Do you have any of the following researcher ID (Google scholar, } \\
\text { SCOPUS or Orchid or Thomson Routers) }\end{array}$ & 41.67 & 53.33 & 3.33 \\
\hline 15. & $\begin{array}{l}\text { Do you know your citation metrics and h index calculated by } \\
\text { above said Online researchers IDs when you enrol yourself ? }\end{array}$ & 26.67 & 68.33 & 5 \\
\hline
\end{tabular}

After analysing the data we found that, $43.33 \%$ have heard of the term called 'Scientometric' even after $63 \%$ of them attending the training programme.

Out of which, $53.33 \%$ of them read the recommendations by International committee of Journal of medical editor's guidelines for publication at least once and $58.33 \%$ were familiar with guidelines to write scientific paper. $56.67 \%$ knew what is COPE - Committee on Publication ethics and were following the ethics according to it. $66.67 \%$ knew that their paper will undergo Editorial - Peer review - Technical - Linguistic Review 
When it was about language and plagiarism, $68.77 \%$ were conducting language check before submission but hardly $39.12 \%$ were checking for the Plagiarism which indicates the probability of fake publications. Only 58.33\% know about SCI - Science Citation Index and that too only $41.67 \%$ of them were selecting the journal for publication based on impact factor by Thomson routers analysis. Among the participants, $38.33 \%$ knew about $\mathrm{H}$ index and hardly $6.67 \%$ measuring the journal's $\mathrm{H}$ index before submitting their articles.

Among of 60 health care professionals, $41.67 \%$ have their researcher ID in Google scholar/SCOPUS or Orchid or Thomson Routers but very few about $26.67 \%$ knew that citation metrics and $\mathrm{h}$ index calculated by above said Online researchers IDs

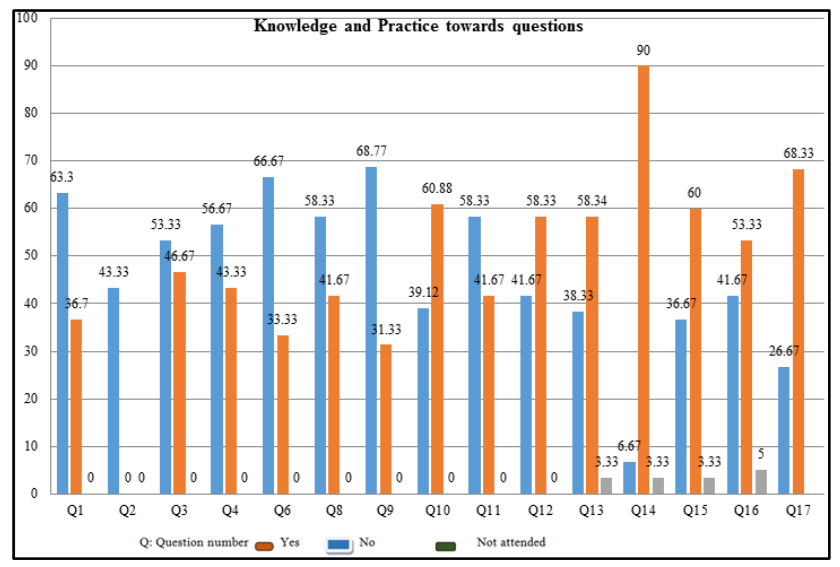

Fig. 1: Knowledge and practice towards questions

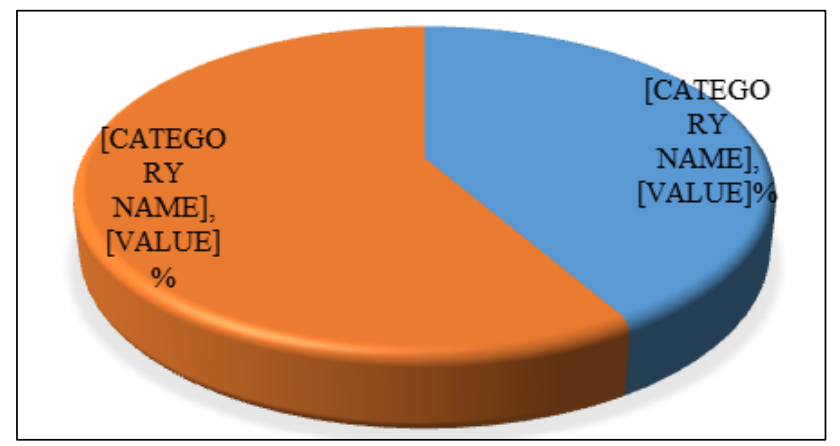

Fig. 2: Practice - Impact factor

Out of 60 healthcare professionals, Only $41.67 \%$ of them were selecting their journals based on impact factor. This shows the quality of the scientific papers, as the rest $58.33 \%$ might have published with less impact factor.

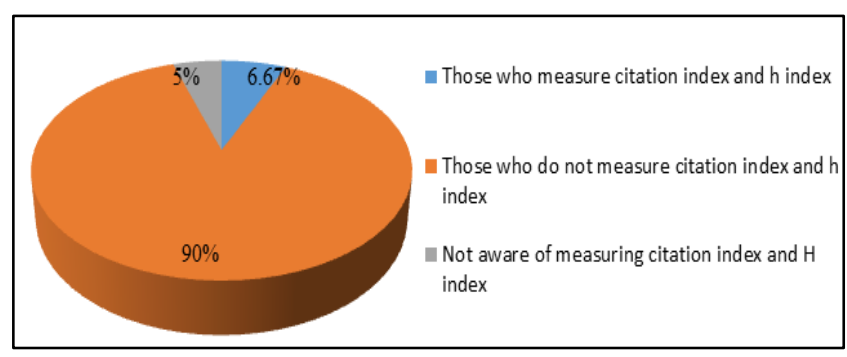

Fig. 3: Practice - Citation index and h index

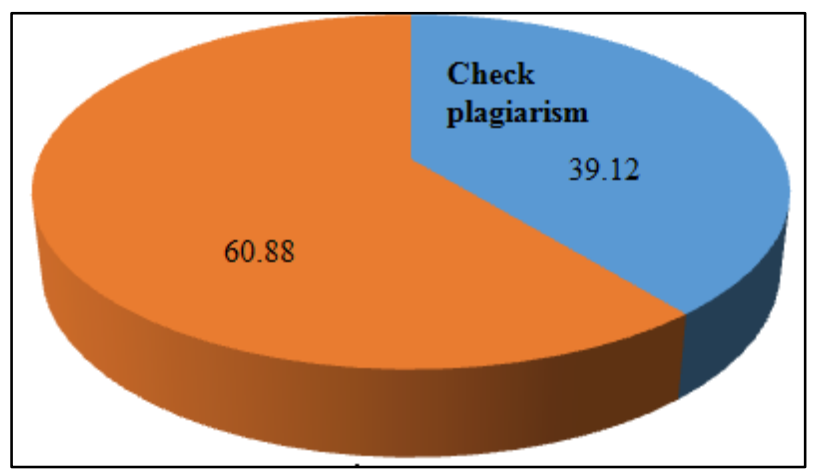

Fig. 4: Practicing Plagiarism

Out of 60 healthcare professionals, Only 39.12 of them check for the plagiarism. Rest others are either unaware how to check for the plagiarism or they might be thinking it must be done by the editors after submission

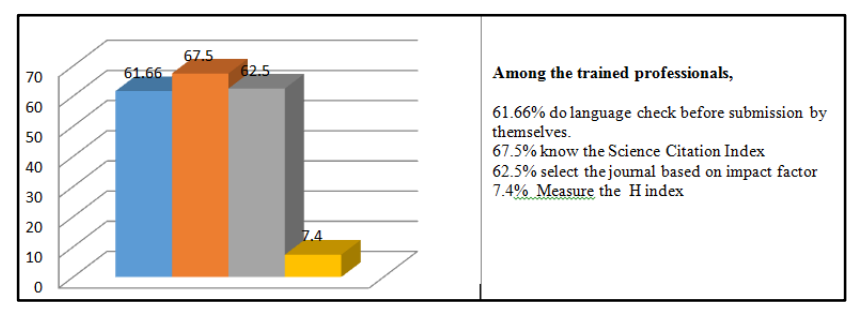

Fig. 5: Analysis of knowledge of different aspects among the professions who have attened training

\section{Discussion}

Scientific and professional research work is the primary educational tool to upgrade our knowledge. Scientists place their scientific work and experience in the common treasury of universal knowledge and at the same time is free to use the knowledge of other researchers. So it should have international standards by application of scientific methods and codes of conduct in scientific research are essential to science and its work to protect it against all forms of dupery 1 
So far, only $8.83 \%$ of Scientometric study have been conducted in India 2

Assessment of the achievement of every scientist, and thus indirectly determining his reputation in the scientific community of these publications, especially journals, is done through the impact factor, which shows how many times a scientific article in a specific journal receives an average number of quotes. 3

According to our study, $58.33 \%$ of the health care professionals were familiar with different guidelines to write their scientific paper. Hopewell $\mathrm{S}$ et al says that The CONSORT Statement provides recommendations for reporting randomized controlled Trials. $63 \%$ were less clear in their recommendations. Very few journals mentioned the CONSORT extension papers. 4

Almost 69\% were check for the language and grammar before forwarding their article for publication. Rest others found it is waste of their time and anyways it will be corrected under editorial review. Few mentioned that they are facing lack of time to do check.

We found that very few, $39.12 \%$ of the participated professionals were checking for the plagiarism before submitting their research work for publication. Many were not having an idea about, from where to analyse for the Plagiarism and most of them thought that when they site an article, it must contain the same words and sentences5, so they were just copying as it is in that cited in their publication. This in turn may lead to publication of most plagiarised article without intension.

The impact factor of a journal reflects the frequency with which the journal's articles are cited in the scientific literature.6A strength of the h-index is it evaluates quantity (evaluated by the number of publications) and quality (evaluated by the number of citations of publications). The $\mathrm{H}$-index is, therefore, little affected by researchers who publish a high volume of low-impact papers or those who only have a few, high-impact publications.7In our study, among 60 participated health care professionals, average number of publications were 87 less than $50 \%$ were not having idea about the $\mathrm{H}$ index and Impact factor of the citation they have used in their journal. Many of them were not aware how to calculate Impact factor of the journal and $\mathrm{H}$ index. This may decrease the quality of their publication though they have conducted good clinical research. And if the citation which they have quoted has the less impact factor, the current publishing author's article will also have less weightage. Number of citation of the present author will also be decreased by indirectly reducing the Impact factor of his articles.

Online research IDs will provide Impact factor, Citation metrics and $\mathrm{H}$ index when the author upload their publication. Many of our participated health care professionals were not aware of this though $41.67 \%$ of them has their IDs in various sites.

Finally we came across the opinion that that, among the $63.30 \%$ of the participants who had attended the training programme regarding Clinical trial, Guidelines for publication, Article writing and Author's criteria were not updated their knowledge. More than $50 \%$ of them have attended this training during their post-graduation. Many said that as the publications have made mandatory, they are lacking time to check all these factors.

\section{Conclusion}

1. Language and plagiarism checks to avoid being tagged plagiarist and avoid being lulled by fake journals

2. Every investigator must be made aware of terms like citation index, impact factor and $\mathrm{H}$ index before writing/submitting their article for publication.

3. Conduct workshops/programmes in view of update on current trends and key notes to improve their publication credibility and quality.

\section{Source of Funding}

None.

\section{Source of Funding}

None.

\section{References}

1. Masic I. Ethical aspects and dilemmas of preparing, writing and publishing of the scientific papers in the biomedical journals. Acta Informatica Medica. 2012;20(3):141.

2. Mooghali A, Alijani R, Karami N, Khasseh AA. Scientometric analysis of the scientometric literature. Int $J$ Inf Sci Manag (IJISM) 2012;18;9(1):19-31. 
3. Saha S, Saint S, Christakis DA. Impact factor: a valid measure of journal quality?. J Med Library Assoc 2003;91(1):42.

4. Hopewell S, Altman DG, Moher D, Schulz KF. Endorsement of the CONSORT Statement by high impact factor medical journals: a survey of journal editors and journal'Instructions to Authors'. Trials 2008;9(1):20.

5. Bazdaric K. Plagiarism detection - quality management tool for all scientific journals. Croatian Med J 2012;53(1):1-3.

6. Doja A, Eady K, Horsley T, Bould MD, Victor JC, Sampson $\mathrm{M}$ et al. The h-index in medical education: an analysis of medical education journal editorial boards. BMC Med Educ 2014;14(1):251.

7. Martínez MA, Herrera M, López-Gijón J, Herrera-Viedma E. H-Classics: Characterizing the concept of citation classics through H-index. Scientometrics 2014;98(3):197183.

8. Bornmann L, Marx W. The $\mathrm{h}$ index as a research performance indicator. Eur Sci 2011;37(3):77-80.
9. Bamidis PD, Lithari C, Konstantinidis ST. Revisiting Information Technology tools serving authorship and editorship: a case-guided.

10. Van Spall HG, Toren A, Kiss A, Fowler RA. Eligibility criteria of randomized controlled trials published in highimpact general medical journals: a systematic sampling review. Jama 2007;297(11):1233-40.

11. Jacques TS, Sebire NJ. The impact of article titles on citation hits: an analysis of general and specialist medical journals. JRSM Short Rep 2010;1(1):1-5.

How to cite this article: Manjula MJ, Nalini GK, Rathod G. A study to assess the knowledge of Scientometric among health care professionals. Int $J$ Comprehensive Adv Pharmacol 2019;4(4):139-43. 